\title{
CONVERSACIONES, DIÁLOGOS Y TRIÁLOGOS DURANTE LA GUERRA DE LA INDEPENDENCIA ESPAÑOLA
}

\author{
María Mercedes Romero PeÑa
}

\section{RESUMEN}

Analizamos en estas páginas los diálogos patrióticos y políticos que se compusieron durante los años de la invasión napoleónica en España. Unos tuvieron como fin primordial impulsar a los españoles a la lucha, y otros fueron reflejo de las rivalidades políticas del momento. Ofrecemos sus características principales y comentamos una selección de los diálogos más famosos y que más difusión tuvieron en su época.

Palabras claves: Literatura patriótica, Guerra de la Independencia, Diálogos.

\section{ABSTRACT}

In the following pages, we will analyze the patriotic and political dialogues that were composed during the Napoleonic invasion in Spain. Some had the essential purpose of urging the Spaniards to fight, others show political rivalries at that moment. We talk about its main features and we comment a selection of the most famous and well known dialogues at that time.

Key words: Patriotic literature, Independence War, Dialogues.

La época histórica en la que centramos estas páginas es un período de grandes conmociones sociales ${ }^{1}$. Fernando, príncipe de Asturias se alzó en el trono español el 19 de marzo de 1808, después de que el Motín de Aranjuez destituyera a Godoy y Carlos IV renunciase a su corona. Pero poco tiempo duró su primer reinado, pues fue engañado y conducido a Bayona, donde el Emperador francés consiguió de él que renunciase al trono, y así fue nombrado rey de España José Bonaparte. El pueblo español se levantó contra la invasión gala en defensa de su monarca, su patria y su

${ }^{1}$ Acerca de la historia del primer tercio del siglo XIX español, véase: Josep FONTANA, La crisis del Antiguo Régimen. 1808-1833, Barcelona, Crítica, 1979; José Luis ABELLÁN, Historia del pensamiento español IV: Liberalismo y romanticismo (1808-1871), Madrid, Espasa-Calpe, 1984, y Miguel ARTOLA, La España de Fernando VII, Madrid, Espasa-Calpe, 1999. 
religión, y comenzó así la Guerra de la Independencia (1808-1814). Durante la contienda, el Consejo de Regencia reunió las Cortes en Cádiz y se redactó la primera Constitución liberal de España, aprobada por las Cortes en 1812. Las derrotas de las tropas francesas llevaron a la firma del Tratado de Valençay el 11 de noviembre de 1813 por el que la Corona española era devuelta a Fernando VII. El ejército invasor abandonó la capital en mayo de 1813, y la población reaccionó con una explosión de entusiasmo patriótico que duró todo un año y que acabó con la vuelta de «El Deseado», que derogó la Constitución y restauró el sistema absolutista.

Estos acontecimientos tuvieron una repercusión inmediata en la literatura española, que se convirtió en un fenómeno prioritariamente político y social, sirviendo de impulso para la lucha y la resistencia heroica. En los meses en los que la capital permaneció libre de ocupación surgieron la poesía patriótica, el teatro de urgencia y la llamada literatura de la resistencia. La mayoría de los escritos literarios fueron composiciones utilitarias, politizadas, en contacto con la historia coetánea y que pretendían orientar al país ${ }^{2}$. Uno de los géneros más utilizados a lo largo de toda la lid fue el del diálogo o la conversación, fórmula literaria muy utilizada en el siglo XVI (el diálogo clásico o renacentista), que presenta una conferencia entre dos o más personas que alternativamente discurren, preguntándose y respondiéndose. Se trata de una fórmula entre el ensayo, cercano a la literatura didáctica, el parateatro y el diálogo teatral, cuyo uso escénico es poco frecuente, aunque el Diccionario de Autoridades lo define como «conferencia escrita o representada» ${ }^{3}$. Estos diálogos, fruto de la Guerra de la

${ }^{2}$ La bibliografía esencial centrada en la literatura surgida durante la Guerra de la Independencia se comprende en los estudios de Emilio COTARELO Y MORI, Isidoro Máiquez y el teatro de su tiempo, Madrid, Imprenta de José Perales, 1902; Jorge CAMPos, Teatro y sociedad en España (1780-1820), Madrid, Moneda y Crédito, 1969; Emmanuel LARRAZ, Théâtre et politique pendant la Guerre d'Indépendence espagnole, 1808-1814, Aix-en-Provence, Université de Provence, 1988 ; Ana María FreIRE, Poesía popular durante la Guerra de la Independencia, Valencia, Grant \& Cutler, 1993, «El definitivo escollo del proyecto neoclásico de la reforma del teatro. (Panorama teatral de la Guerra de la Independencia)», en AA.VV., Teatro español del siglo XVIII, ed. de José María Sala Valldaura, Lleida, Universitat, 1996, pp. 377-396 y «La literatura española en 1808», Revista de Historia Militar, 2 (2005), pp. 267-284; David T. Gies, El teatro en la España del siglo XIX, Cambridge, University Press, 1996; Emilio PaLACIOS FERNÁNDEZ y Alberto ROMERO FERRER, «Teatro y política (1789-1833): Entre la Revolución Francesa y el silencio», en Joaquín ÁlvAREZ BARRIENTOs (ed.), Se hicieron literatos para ser políticos. Cultura y política en la España de Carlos IV y Fernando VII, Madrid, Biblioteca Nueva, 2004, pp. 185-242; A. ROMERO FERRER, «Poesía y cambio político (1789-1833)», en J. ÁlvareZ BARRIENTOS (ed.), Se hicieron literatos para ser políticos, pp. 167-185; y María Mercedes ROMERO PEÑA, El teatro en Madrid durante la Guerra de la Independencia (1808-1814), Madrid, FUE, 2006.

${ }^{3}$ Diccionario de Autoridades, Madrid, Imprenta Francisco del Hierro, 1732, III, p. 262. Esta acepción desaparece de los diccionarios de 1791 y 1803. 
Independencia, los estudiamos con la idea de afrontar el texto literario sin demasiado apego a la calidad estética, de la que la mayoría carece, sino más bien, el aspecto ideológico y el contexto social que refleja. Aunque están muy lejos del hálito literario de la buena literatura no se les puede quitar el mérito de encontrar en ellos un testimonio contemporáneo y una fuente de transmisión del clima psicológico que se vivió durante la campaña propagandística. Indudablemente, constituyeron una forma de expresión artística que contenía la realidad de su entorno. Los diálogos, al igual que sucedió con otros géneros y subgéneros dramáticos que se escribían guiados por un fuerte compromiso, no siempre se correspondieron con las exigencias formales y estéticas, y es que el único propósito de los autores, anónimos en su mayoría, fue el de sacar adelante unos textos, ya fuese para ser leídos o representados, en los que, en ninguno de los casos, se consideraba la perfección formal como el primordial de sus objetivos. Probablemente estas composiciones tuvieron una circulación reducida, a pesar de que alguna de ellas contó con ediciones impresas; pero el eco de todas se apagó con el fin de la guerra.

Los diálogos patrióticos y políticos son textos generalmente breves, y la estructura de su argumentación es muy simple. En los que vamos a comentar a continuación (no todos los que se escribieron, sino sólo una selección de los mismos) descubrimos los mismos elementos: simplismo en la composición, exaltación de la religiosidad hispana frente al ateísmo y barbarie del galo, ejemplos de patriotismo, escenarios inmutables, maniqueísmo de buenos y malos, personajes esquemáticos, sin caracterizar, retrato de la ínfima maldad de Napoleón y de la suprema bondad de Fernando VII, etc. No es de extrañar esta pobreza psicológica, pues los interlocutores suelen ser portavoces de una ideología y transmisores de una lección moral. Sólo tratan de exaltar, directa o indirectamente, la heroicidad e indomabilidad de los españoles, y la ridiculización de los enemigos, sean quienes sean. Es más, muchas veces el contenido, por su estilo directo y vivencial, a pesar de su pobreza en el resto de los aspectos, era capaz de convertir la ficción en realidad y provocar una invitación directa a la acción. Tampoco se daba importancia, con escasas excepciones, a las descripciones de paisajes, a la señalización del tiempo o al vestuario de los personajes. Su aspecto más característico es la inmediatez respecto a los hechos que las dictan y su carácter esencialmente popular, explica Ana María Freire, «por su propia concepción, por el público al que va destinado y hasta por la misma identidad de los autores, desconocidos tantas veces y portavoces de un sentir colectivo» ${ }^{4}$. El estilo de los diálogos huye del cultismo para hablar en una

${ }^{4}$ A. M. FREIRE, «Teatro político durante la Guerra de la Independencia», en Víctor GARCÍA DE LA CONCHA (dir.) y Guillermo CARNERO (coord.), Historia de la literatura española. Siglo XVIII, Madrid, Espasa-Calpe, 1995, II, p. 879. 
clave más cercana al pueblo; habitualmente sólo encontramos en ellos un lenguaje popular directo, más prosa que verso, y hechos de fácil comprensión, con una expresión sencilla y accesible. El vocabulario que encontramos es interesante pues refleja, en muchos casos, el primer glosario social y político del liberalismo español ${ }^{5}$. Tampoco podemos olvidarnos del léxico satírico característico de muchas de estas piezas, humorísticas algunas de ellas, pues se transformó en una gran palestra ideológica de crítica a todo lo francés.

Del subgénero del triálogo, una conversación entre tres interlocutores, sólo contamos con un ejemplar, importante, pues no sólo fue escrito, sino también representado durante la Guerra de la Independencia: El sueño del tío José, que quiso ser primero y quedó cola ${ }^{6}$, anunciado en la Gaceta de Madrid del 14 de octubre de 1808 como pieza original fácil de ejecutar en cualquier casa por tener solas tres personas. La obra venía precedida de unos versos pertenecientes a la comedia El que fuere bobo no camine, de Tirso de Molina: «Altos pensamientos locos, / hagamos cuenta que ha sido / lo que por mí pasó un sueño».

El triálogo se sucede entre el tío Pepe, «pretendiente que llevó calabazas», Pierres, amolador, su confidente, y Jaques, sartenero, «amigo de los dos $y$ de qualquiera». Estos dos últimos personajes, representantes de la clase más baja del pueblo, la que podríamos llamar de baja estofa, son muy apreciados por José I en esta pieza, tanto que llega a decir que «todos somos uno», y a ellos es a quienes les relata el motivo por el que tiene triste el corazón:

\author{
«Mi hermano Napoleón, \\ cuyos sutiles enredos \\ no son todos los demonios \\ capaces de comprenderlos, \\ ha sabido enredar mucho; \\ y tanto, que yo me temo, \\ que del último, que es éste, \\ de enredar acabaremos». (p. 17)
}

Narra las malvadas hazañas de su hermano haciendo un vil parangón con Don Quijote, que andaba por el mundo «desfaciendo tuertos», motivo literario que es común en otras obras del momento. Después de relatar sus

5 Juan Francisco FUENTES, «Aproximación al vocabulario socio-político del primer liberalismo español (1792-1823)», en Jean RENÉ AYMES y Javier FERNÁNDEZ SEBASTIÁN (eds.), La imagen de Francia en España (1808-1850), Bilbao, Universidad del País Vasco, 1997, pp. 51-62; y A. Calderone, «El lenguaje del liberalismo y del absolutismo en el teatro político», Romanticismo, 2 (1984), pp. 38-46.

${ }^{6}$ El sueño del tío José, que quiso ser primero y quedó cola, triálogo, Madrid, Imprenta de Repullés, 1808. Se conservan varios ejemplares en diferentes bibliotecas, algunos de ellos con el título de la segunda versión que se realizó: El sueño del tío José, que ha hecho el papel de Rey de las Españas, Málaga, Imprenta de Martínez, s.a. 
supuestas proezas por otros países, todo maldades y nada bueno, reconoce que al Emperador le tentaron los demonios «que le están siempre influyendo» el hacer feliz a España, y va contando su silenciosa entrada en la península, la marcha de Murat, la derrota de Bailén, para acabar en una sarta de improperios contra su hermano:

«¿Para qué, ingrata fortuna,

para qué, hermano el más fiero

que hai entre las hermandades,

me hiciste venir corriendo

para volverme corrido?» (p. 18)

En una colección de folletos del día, titulada Diversiones nocturnas de la presente época ${ }^{7}$ se recoge un Diálogo joco-serio entre un caballero napolitano de la comitiva de Josef Napoleón, intruso Rey de España, y el alcalde de Tioja, cerca de Burgos ${ }^{8}$ que contó con varias ediciones y mucha difusión durante los primeros años de la contienda. En este diálogo en prosa el napolitano le pide al alcalde que le explique con franqueza e ingenuidad qué es lo que generalmente se dice del nuevo rey y de toda la familia del gran Napoleón «ínterim espero se pase el sol para proseguir el viage, seguro de que quanto me diga Ud. quedará sepultado en el centro de mi corazón». Le contesta el alcalde que poco puede contarle, pues escasas eran las noticias que llegaban al pueblo, ya que de las gacetas no podían sacar nada en limpio porque todas desmentían lo que contaba la de Madrid, creyendo generalmente que es ésta la que engañaba ya que la hacían los gabachos. Va relatando el alcalde de una forma un tanto ingenua todo lo que ha ido llegando a sus oídos de la familia de Bonaparte desde su nacimiento, y después de dialogar sobre el tema de la República francesa ${ }^{9}$ y de lo que ha hecho el Emperador en su propio país, el alcalde se niega a reconocer a José I como rey, adornándolo con toda una serie de nuevos apodos: «¿Cómo don José Napoleón? ¿el tío Pepe? ¿el Juse-pillo? ¿el potrilla? ¿el coloso de Rosas? ¿el siete quartas? ¿el dios Baco?» (p. 6). Utiliza el lenguaje taurino para hablar de las victorias de los españoles: «Hemos tenido ya varias corridas, las ha habido en Bailén, Mallén, Zaragoza y Valencia, y habiendo sido muy bravos los toros, nuestros toreros han

${ }^{7}$ Diversiones nocturnas de la presente época, o colección de papeles en prosa y verso, jocosos y serios, Tomo I, Madrid, Imprenta de Vega y Compañía, 1808. Dice en la introducción: «Paisanos y amigos míos, os miro divertidos por el día y las circunstancias con tanto papel como sale en la prensa, y así será razón que para estas noches que se aproximan dilatadas tengáis con quien entreteneros» (f. 1r).

${ }^{8}$ Diálogo joco-serio entre un caballero napolitano de la comitiva de Josef Napoleón, intruso Rey de España, y el alcalde de Tioja, cerca de Burgos, Valencia, Oficina del Diario, 1808.

${ }^{9}$ Hablando de ella dice: «Mas fue tan poco durable / de esta Amazona el poder / que apenas fue concebida, / quando le quitó la vida / el mismo que la dio el ser». 
sabido picarles con tanta fuerza que siempre han quedado los toros muertos en la plaza» (p. 28), y después de nuevas arengas del de Tioja defendiendo la causa de la península, se queda convencido el napolitano de las razones de los españoles y se marcha pensando en aconsejar a José I que se vuelva a Nápoles.

Muy típicas son las composiciones dialógicas en las que uno de los personajes, el que lleva la voz cantante, es o el alcalde, como la que acabamos de ver, o el cura, verbi gracia, la Conversación entre el tío Antón, arriero, y el Cura de su lugar ${ }^{10}$, en la que este último espera ansioso noticias de Valencia para saber qué se está haciendo por liberar a la nación, y expresa esperanzado: «La Patria es nuestra madre, está tan enferma como todos sabemos, y qual nunca se ha visto. Una gangrena pestífera la va devorando, pero gracias a la divina asistencia, y a la prudente vigilancia de los que nos gobiernan, que se va cortando por momentos» (p. 1). Afirma el arriero que la gente sencilla y sin letras conoció antes que los eruditos esta gangrena que se acercaba a España, y copia unas coplas con glosa que compuso por entonces manifestando este pesar:

«Una sutil sanguijuela
a la España se aferró:
poquito a poco la amuela
después que la desangró». (p. 2)

Pero al tiempo ofrece las buenas noticias al cura de que Junot se ha rendido en Lisboa, que el marqués de la Romana ha embarcado en buques ingleses para España, y que se están arreglando las milicias: batallones de honor que se componen de hombres honrados. El cura, que como muchos otros se hizo literato por las circunstancias de la guerra, le entrega sus papeles en los que anima al patriotismo para que el arriero los lleve a imprimir a Valencia, convencido de que, además de ser el gran comercio del día, «hacen mucha guerra. Quánto han vencido los franceses sólo con los escritos y papeles!» (p. 8).

Otro cura, párroco de Aldea Leal, es el protagonista de un diálogo que tiene por objeto la burla y escarnio de la Constitución de Bayona, en La quema de la Constitución en Aldea Leal, por el doctor Don Patricio Espa$\tilde{n} o l^{11}$. En este pueblo se juntaban todas las noches en casa del párroco el escribano y otros dos aldeanos, Silvestre y Perico, que conversaban amplia y discretamente sobre los sucesos del día y, en una de las noches decidieron, en un acto de patriotismo y valentía, dar al fuego la Constitución Napoleaniana, con un claro recuerdo de la quema de la dañina biblioteca del

${ }^{10}$ Conversación entre el tío Antón, arriero, y el Cura de su lugar, Valencia, Viuda de Agustín Laborda, 1808.

${ }^{11}$ La quema de la Constitución en Aldea Leal, por el doctor Don Patricio Español, Valencia, Burguete, 1808. 
hidalgo don Quijote. El cura sentenció dicho escrito a las llamas «por las muchas judiadas que quería hacer con nosotros los buenos españoles y cristianos viejos, particularmente la de darnos por rey un hombre sospechosos en la fe» (p. 13).

Otro tipo de diálogo muy habitual que encontramos en 1808 es el protagonizado, siempre de forma burlesca, por Napoleón o alguno de sus acólitos, como el titulado Diálogo que supone un curioso americano entre Napoleón y su senador Beauharnais, con respecto a las cosas de España, atendido el carácter de ambos ${ }^{12}$. En él leemos que a las preguntas del Emperador, extrañado de la resistencia que ha encontrado en España, le va contestando Beauharnais declarándole el verdadero valor de los hispanos, que lucharon todos unidos por querer ser regidos por su soberano legítimo. No se explica Napoleón por qué los españoles hicieron de Fernando su rey predilecto cuando siempre ha sido inexperto, oscuro y encerrado, y tampoco entiende por qué ha reaccionado de forma tan negativa al gobierno de José I, a lo que le contesta el Embajador:

«Si a la España le era doloroso el cambiar del dominio de una familia reverenciada por los abuelos de sus abuelos, le era afrentoso que una mano extranjera, y desautorizada, sin más pretexto ni más medios que las felonías y engaños, se la arrancase. La tolerancia de la Nación española se ha tenido equivocadamente por debilidad» (p. 5).

Y no duda en exponerle claramente cómo es odiado por todos los españoles y cómo le van a desafiar hasta el final, pues España ha jurado no vivir sino libre y sin mancilla. Ante estas claras palabras, Napoleón, enfurecido, le contesta:

«Estos insultos mismos que propalas reclaman mi venganza; y mi seguridad pide ya el exterminio de unos pueblos que habiendo roto la balla del respeto, que al menos me aparentaban los que no me lo tenían, me han dexado al descubierto de toda la Europa; y que quitando una piedra de los cimientos del edificio de mi ambición, le dexa expuesto a arruinarse más precipitadamente que se ha levantado» (p. 11).

Ante las ofensas de Napoleón, Beauharnais continúa defendiendo el honor de los españoles, sus virtudes y su heroica actitud.

En la divertida Conversación que tuvo el Príncipe Murat con don Manuel Godoy, relativa a los sucesos de España ${ }^{13}$, ambos degradados personajes se echan las culpas mutuamente de sus desgracias y pérdidas. La obra es de escaso valor literario y está escrita en octavas asonantadas. Murat,

12 Diálogo que supone un curioso americano entre Napoleón y su senador Beauharnais, con respecto a las cosas de España, atendido el carácter de ambos, Cádiz, Imprenta de la Viuda de Don Manuel Comes, 1808.

${ }^{13}$ Conversación que tuvo el Príncipe Murat con don Manuel Godoy, relativa a los sucesos de España, Madrid, Imprenta y Librería de Collado, 1808. 
después de las recriminaciones, reconoce que España es valerosa y que abrigaba muchos tesoros que no habían sabido ver. Afirma que mintió a los españoles sin cesar, mas que se engaña en todo el orbe entero, para hacerles creer sus deseos de regeneración y las proclamas de paz y felicidad. Haciendo una interesante mención a la literatura patriótica, en la que él nunca salió bien parado, amargamente se queja: «Hice escaso el papel, cansé la imprenta, mandé que los más fértiles ingenios exercieran el fuego de su ciencia: mentí en desierto. Vi leer lo carteles de comedias de la más despreciable y pobre fama con mucho más fervor que una proclama» (p. 4).

También es protagonista el duque de Berg del Diálogo entre Napoleón y Murat, quando éste se presentó a aquel en Bayona, del regreso vergonzoso de España a Francia ${ }^{14}$, donde dice al gran Emperador un hecho que efectivamente ocurrió y siempre quedó en la memoria de españoles y franceses para oprobio de estos últimos:

«Yo proclamé a José tu hermano; pero la ciudad de Burgos no sólo cerró sus oídos, sino también las puertas y ventanas de sus casas; y les prometieron novillos, ni se hallaron éstos ni menos espectadores, y toreros. Se les concedió entrada franca en el patio de comedias, y sólo asistió, conducido de la fuerza, el Intendente» (p. 4).

En el diálogo también interviene el ministro Talleyrand, que recrimina a Bonaparte por su conducta y le aconseja que devuelva el trono que ha usurpado y ponga en libertad a Fernando VII. Otro diálogo de semejante título, pero en verso, es el Largo discurso que tuvieron Napoleón y Murat después que regresó éste de España a Francia ${ }^{15}$, en el que haciendo referencia al mismo hecho, le dice el duque de Berg a su cuñado:

«Grande Emperador de Francia
no han servido nuestras fuerzas
para conquistar la España,
ni sirvieron las promesas
que a todos generalmente
les hice, para que vieran
que les daría descanso,
y con él muchas pesetas,
toros para divertirse,
porque aficionados eran;
botillerías de valde;
no pagar en la comedia,
y de todas estas mandas
no lograré una siquiera» (p. 1).

${ }^{14}$ Diálogo entre Napoleón y Murat, quando éste se presentó a aquel en Bayona, del regreso vergonzoso de España a Francia, Isla de León, Imprenta Real de Marina, s.a.; Reimpreso en Francia, por Don Luis Carreras e Hijos, s.a.

${ }^{15}$ Largo discurso que tuvieron Napoleón y Murat después que regresó éste de España a Francia, Valencia, Benito Monfort, s.a. 
Murat habla con franqueza al Emperador reconociendo que nada hay que hacer en España porque no se puede vencer al valor hispano con los soldados. Hace un repaso del heroísmo español en las diferentes ciudades de la península y propone como único remedio a la desolada situación del francés en España la pronta restitución de Fernando.

En la Conversación o coloquio de Josef Bonaparte, pretendido rey de España con Marquina, otros y las Botellas, de resultas del buen tratamiento que le dieron los madrileños el día primero de agosto de este presente año, que fue por la tarde a pasearse al Prado ${ }^{16}$ se descubre por supuesto autor de la misma un oficial de la servidumbre de Pepe Botellas que reproduce un diálogo entre aquellos que nunca se separaban de José: Negrete, Marquina, Savary, Belliard y Frías. Expresaba Bonaparte en dicha conversación que el pueblo de Madrid le tenía vuelto el juicio ya que, o no había gente o ésta se escondía al verle. Todos sus satélites le afirman que sí la hay: Marquina por las multas que ha puesto, Savary por los pasaportes, Belliard por las limosnas y, ante esto, José propone que a la población se la ha de tratar con cariño, no con la fiereza de Murat, y sugiere darle alguna diversión. Frías contesta: «Como estoy hecho a mantener a mis expensas cómicos y toreros, juzgo será acertado conceder a los madrileños unas corridas de toros y algunas comedias de valde.» A Bonaparte le parece muy buena idea y sale ufano al Paseo del Prado para dejarse ver, pero los pocos que allí había se retiraron por no saludarlo. Vuelve desconsolado y pide su «tren acostumbrado para dormir», consistente en dieciocho botellas de vinos diversos. Aquí empieza un monólogo, añorando sus felices días de Nápoles, culpando a su hermano de su situación presente y se dirige en un sentido soliloquio a su cajón de licores: «seno que contiene el licor que alegra el corazón del hombre, disipa mis melancolías entrando en mi posesión.» Comienza a sacarlas pero descubre que todas ellas le traen pesar, el vino de Jerez le recuerda a la derrota de Bailén, el de Tudela al poco exitoso sitio de Zaragoza, el de Valdepeñas a la tierra manchega de la que huyeron los franceses, el de Malvasía le hace acordarse de los estragos de Valencia y Cataluña. A pesar de que todas le amedrentan, no tiene reparo en consumir su contenido, por lo que con ellas se consuela y se queda finalmente dormido.

De 1809 es el diálogo en prosa de Francisco Meseguer ${ }^{17}$ El don Quixote

${ }^{16}$ Conversación o coloquio de Josef Bonaparte, pretendido rey de España con Marquina, otros y las Botellas, de resultas del buen tratamiento que le dieron los madrileños el día primero de agosto de este presente año, que fue por la tarde a pasearse al Prado, Madrid, Imprenta de Agapito Fernández Figueroa, 1808.

17 Francisco Meseguer (1760-1810) nació en Murcia y estudió medicina en Valencia. Fue uno de los fundadores del Correo Literario de Murcia (1792-1795), donde publicó una colección de fábulas. Es autor del famoso diálogo contra Napoleón: El Don Quixote de ahora con Sancho Panza el de antaño (Murcia, s.n., 1809), además del 
de ahora con Sancho Panza el de antaño ${ }^{18}$. El autor nos sitúa en un ameno valle donde se sentó a reposar después de perseguir inútilmente a una bandada de perdices hasta que fue alterado por unas voces:

«Me acerqué tanto quanto bastó para descubrir sin ser visto un hombre de poca estatura, armado como suelen los coraceros franceses, y en su espaldar un cartelón que decía: este es el Caballero de la mala figura. Enfrente, y de cara a mí, sentado sobre una albarda, y con la mano en la mesilla en ademán de hombre melancólico y pensativo, descubrí a otro, manchego al parecer, según indicaba el vestido que traía. Un asno rucio y un caballo flaco pacían libremente por allí cerca. Desde luego me ocurrió que esta escena tenía no poca semejanza con alguna de las que ofrece la historia de don Quixote: apliqué pues el oído, y fixé mi atención en el diálogo siguiente, que me dio a conocer bien pronto a los dos personajes, que eran a saber, nada menos que el señor Napoleón Bonaparte y el mismísimo Sancho Panza: el que reflexione que yo soñaba, disimulará el grandísimo anacronismo que supone mi narración» (pp. 3-4).

El diálogo nos presenta a Sancho, lleno de penas, que no quiere desahogarse contándoselas a Napoleón, aunque éste le da la palabra de que no lo interrumpirá ni mucho menos le dará con el lanzón a pesar de lo que dijere, pero Panza no confía en su palabra después de lo que le ha pasado a Fernando VII. Bonaparte, con su labia, trata de convencerlo de que él es un héroe como César, Atila o Alexandro, y que sólo mira por lo que le conviene, por lo que sus acciones no se califican por su justicia o injusticia sino por la grandeza del fin al que van destinadas. Sancho, al igual que en la magna obra de Cervantes, se sigue expresando con refranes y su vocabulario es torpe y divertido equivocando palabras y pasando muchos malentendidos, pero siempre razonable y bueno. Le dice Panza que no se compare con su amo, Don Quixote, pues éste trataba de conquistar reinos e ínsulas, pero «como Dios manda», enderezando tuertos, mirando por la honra, peleando contra los malos y defendiendo a los buenos, «pero ud. es otra casta de caballero andante, de los que mi amo llama contrahechos y follones y malandrines» (p. 13). Equivoca Sancho la expresión de «enderezar tuertos» y le dice a Napoleón:

«Y ahí está el hermano de V. M. el señor D. José, que tuerto era, y tuerto es y tuerto será mientras Dios lo tenga en el mundo; y más valía que todo ese empeño que ha tomado V. M. en hacello Rey de España, que será quando la

Diálogo en prosa contra Napoleón y los franceses (México, s.n., 1809), un Diálogo de Bonaparte y Sancho Panza, y El diablo predicador (México, s.n., 1809), de la que existe un ejemplar en la British Library. Con anterioridad a la guerra había escrito La Andria, traducción de la de Terencio, la comedia El Chismoso y Diálogos de Churra.

${ }_{18}$ F. Meseguer, El don Quixote de ahora con Sancho Panza el de antaño. También es Sancho Panza el supuesto autor de una divertida carta plagada de refranes en la que se critica a Murat: Carta que un español escribe a Murat sobre sus aventuras en España, Cádiz, Reimpreso en la Casa de la Misericordia, s.a. [1808]. 
rana tenga pelo, lo hubiera tomado en enderezarlo y remendarle aquel ojo del demonio que tan mal le pega» (pp. 14-15).

De igual modo critica las atrocidades que cometen los ejércitos del Emperador, alaba Sancho la honradez y lealtad de su amo, y denigra a Napoleón por haber abandonado a su primera mujer a fin de obtener más cargos al casarse con otra, cosa que no hizo el hidalgo manchego aun pudiendo haber sido rey al casarse con la reina de Micomicón. También saca a colación su reinado en la ínsula y explica que los insulanos se rieron de su sencillez, pero que los españoles se ríen de la perfidia y torpeza de Napoleón. A partir de este momento, Sancho soltó todavía más su lengua y comenzó una retahíla de insultos al corso, el cual se durmió. Por eso, concluía Meseguer que Bonaparte «no repara en dar motivo para que le digan tales verdades y se duerme quando las oye, como pudiera un cerdo si le rascaran» (p. 34).

Recordamos el divertido coloquio entre dos paisanos, Los ruegos de Menga, Aldeana, a Perote, contra los franceses ${ }^{19}$, escrito en endechas, en el que tras el relato de las atrocidades que cuenta Perote de los invasores, Menga se compromete a juntar a todas las mozas con todos los cacharros de cocina, palos, piedras, etc. para matar a los gabachos, así como donar camisas, greguescos, botines, chalecos, gorros, sombreros y vestidos para los soldados; pero sobre todo, quiere rogar a Dios:

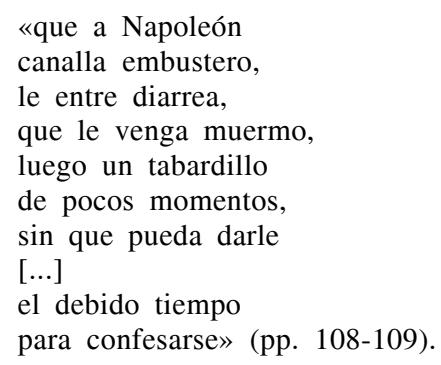

Entre los papeles de la inmensa Colección Documental del Fraile ${ }^{20}$ hemos podido consultar varios diálogos publicados en Méjico y protagoni-

\footnotetext{
${ }^{19}$ Los ruegos de Menga, Aldeana, a Perote, contra los franceses, s.1., s.n., s.a.

${ }^{20}$ Colección reunida por Fray Joaquín de Sevilla. Su verdadero título es: España triunfante de Napoleón, la Francia y todos sus enemigos y se halla en el Servicio Histórico Militar en la sala dedicada a las guerras del siglo XIX. Está constituida principalmente por impresos y la mayoría de ellos corresponden a la Guerra de la Independencia. Contiene todo género de publicaciones de aquella agitada época y nos dan idea del estado político y social de la España de entonces. Su autor reunió los papeles que iban saliendo de las imprentas nacionales y encuadernándolos. La colección se hizo sin orden alguno, atendiendo al tamaño de los impresos por lo que cada volumen es heterogéneo. Hay en total 1.008 volúmenes. La investigadora Ana María Freire ha realizado la importante labor de confeccionar unos modernos índices para su consulta: Índice bi-
} 
zados por personajes de este país, como la Conversación que tubieron un Demandante y una Frutera $^{21}$, en el que ambos conversan sobre las victorias de los españoles que, en inferioridad de condiciones, vencen porque les ayuda la Virgen. También hacen referencia a la infinidad de papeles que salen al día y del beneficio que proporciona el leerlos. Entre ellos citamos también el Desengaño a los indios haciéndoles ver lo mucho que deben a los españoles. Conversación que tuvieron en el campamento de esta Ciudad un Dragón con una tortillera y su marido Pasqual, y la presenció $A \cdot V \cdot{ }^{22}$, en el que el militar les enseña lo que han de agradecer a España y a Fernando VII que les ha llevado paz y les ha quitado tributos.

El Diálogo patriótico. Del Décimo al Decimotercio ${ }^{23}$ reproduce una conversación entre Filopatro, Aceraio y Moros, en la que el primero de ellos, como bien representa su nombre, les explica qué es la patria y quién es un buen patriota. Recuerda además a los defensores distinguidos de Fernando VII, muy dignos por el gracioso e importante servicio militar que están haciendo en Méjico y les hace ver que Napoleón ha atacado a la cabeza (que es España) y que, si ella cae, caerán todos sus miembros, por lo que les anima a no permitir que se muera el enfermo; para lo que es necesario no perdonar gasto alguno en médicos, boticas, asistentes y alimentos.

Muy peculiar por la condición de los protagonistas es la Conversación entre Colamocha y Valiente, caballos empecinados ${ }^{24}$, escrito a imitación del Coloquio de los perros de Cervantes. En la advertencia preliminar explica el autor que se trata de una carta que un joven empecinado envió desde Aragón a un amigo suyo residente en la corte. Dentro del papel jocoso el editor de la carta añade algún comentario serio con respecto a la guerra, como los de los que no tienen con qué abrigarse, o lo pobres que eran las caballerías de los empecinados. El soldado que ha escuchado la conversación entre los caballos interpreta esta charla, en la que ambos animales se han referido sus vidas, como un aviso para que procuren formar una caballería aguerrida, valiente y belicosa.

Otros de los diálogos que se compusieron durante la Guerra de la In-

bliográfico de la Colección Documental del Fraile, Madrid, Servicio Histórico Militar, 1983. Véase también su artículo «Una colección documental del siglo XIX», Castilla, V (1983), pp. 41-45.

${ }^{21}$ Conversación que tubieron un Demandante y una Frutera, s.l., s.n., s.a.

22 Desengaño a los indios haciéndoles ver lo mucho que deben a los españoles. Conversación que tuvieron en el campamento de esta Ciudad un Dragón con una tortillera y su marido Pasqual, y la presenció A. V., s.l., s.n., s.a.

${ }_{23}$ Diálogo patriótico. Del Décimo al Decimotercio, s.1., s.n., s.a.

${ }^{24}$ D. B. Y. H. P., Conversación entre Colamocha y Valiente, caballos empecinados. Imitación de los perros de Mahudes de Cervantes, Madrid, Imprenta de Álvarez, s.a. El mismo autor había escrito también una famosa poesía: Asalto terrible que los ratones dieron a la galleta de los franceses, poema serio en dos cantos, Madrid, Luciano Vallín, 1808. 
dependencia no tenían ya un carácter patriótico, para animar a la lucha y a la resistencia, sino que su creación se debía más a motivos políticos, y en concreto a la lucha entre dos partidos políticos que comenzaban a fraguarse en España: el liberal y el absolutista. Los liberales quisieron configurar una nueva sociedad, pero sabían que para que esto fuese posible, era necesaria la conquista previa del poder político, lo cual llevaba sin remedio a la lucha revolucionaria. Aspiraban a crear una sociedad racionalista, burguesa e individualista. Dentro del grupo de los absolutistas se podían diferenciar dos grupos, el formado por aquellos que eran plenamente reaccionarios y que veían a Fernando VII como el que iba a traer la libertad y la salvación del pueblo contra los herejes franceses, y el constituido por los «realistas», partidarios de reformar el Antiguo Régimen, pero con la voluntad del rey ${ }^{25}$.

Un sacerdote y un alcalde se unieron para conversar y servir de argumento al Diálogo entre el cura de Tortuera y el tío Perales ${ }^{26}$ escrito en versos octosílabos y en el que se hace una crítica, al igual que Mor de Fuentes en su Egoísta o mal patriota, a aquellos que no querían contribuir económicamente a la causa de Fernando y de la independencia española. $\mathrm{El}$ alcalde, con un lenguaje excesivamente vulgar, le explica sus pesares al cura por los mandatos de los empecinados a que les entregue las contribuciones, la plata de la iglesia y la del convento. También aparece como personaje el padre Letor García, que aconseja al alcalde que obedezca a los empecinados y a todo el gobierno, algo en lo que no está de acuerdo el cura. Pero García explica al párroco de Tortuera cómo en la isla de Mallorca había un fraile extranjero que se negaba a pagar los diezmos por la causa del Deseado, y fue impugnado, como era costumbre, por varios papeles: una Carta de Xavier S. Juan, y un Ensayo anónimo; y, a pesar de que el fraile se defendió en una Carta interina, donde a todo le dio un

${ }^{25}$ Consúltese el artículo de Antonio Elorza, «La formación del liberalismo en España», en Fernando VAllespín (ed.), Historia de la Teoría Política, III, Madrid, Alianza Editorial, 1995, pp. 397-447. Opina que las raíces del liberalismo han de buscarse en el esfuerzo reformista que caracterizó al reinado de Carlos III. Véase, para conocer con detalle el surgimiento de las fuerzas liberales en oposición a las absolutistas, M. ARTOLA, Partidos y programas políticos 1808-1936, Madrid, Aguilar, 1974-1975 y Antiguo Régimen y Revolución liberal, Barcelona, Ariel, 1983; Albert DÉROZIER, Manuel José Quintana y el nacimiento del liberalismo en España, Madrid, Turner, 1978; A. ElorZA, La modernización política en España: (ensayos de historia del pensamiento político, Madrid, Endymion, 1990; Joan Antón Mellón y Miquel Caminal BADIA (coords.), Pensamiento político en la España contemporánea (1800-1950), estudio preliminar de A. Elorza, Barcelona, Teide, 1992; Pablo FERnÁndeZ AlbaladeJo y Margarita ORTEGA LóPEZ (eds.), Antiguo Régimen y liberalismo. Homenaje a Miguel Artola, e Irene Castells y Antonio Moliner, Crisis del Antiguo Régimen y revolución liberal en España (17891845), Barcelona, Ariel, 2000.

${ }^{26}$ Diálogo entre el cura de Tortuera y el tío Perales, alcalde del mismo pueblo, que se recibió por el último correo de Valencia y se dirige al P. F. R. S. V., Palma de Mallorca, Imprenta de Miguel Domingo, 1811. 
sentido inverso e inoportuno, fue contestado con una sátira y una burla escritas en prosa y en verso, subtituladas miscelánea o bien sainete casero. En un larguísimo parlamento, el sacerdote patriota, verdadero protagonista del diálogo aunque no está incluido en el título, explica los hechos al de Tortuera haciéndole entender que el dinero que sobra en las iglesias y en los conventos hay que repartirlo entre quienes lo necesitan y que no se deben hacer interpretaciones vanas de los Santos Evangelios:

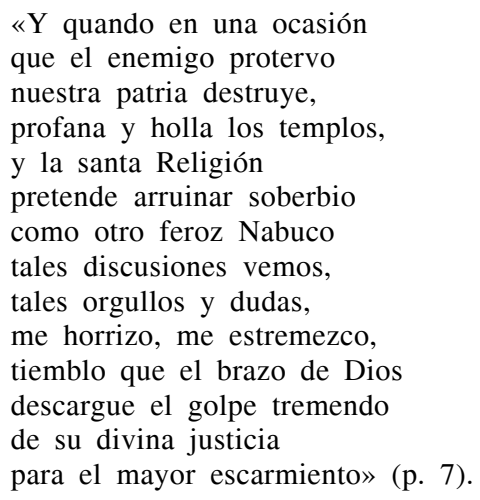

El cura, finalmente, se arrepiente de su egoísmo ante todas las razones expuestas. El autor del diálogo añadía una nota al final del mismo, en la que explicaba que, sin duda, no llegaron a Tortuera, antes de finalizar la conversación, las Apostillas, las Preguntas del Apostillador, las cartas de C. T. A. y otros escritos que publicaron en Palma varios sujetos religiosos y patriotas a quienes el famoso fraile egoísta tuvo la osadía impudente de llamar Club antiimunitario. Si hubiesen llegado, finaliza, el alcalde y el Letor no hubiesen dejado de darles en su diálogo el tributo de elogio que se merecen.

Otro diálogo con los mismo fines, aunque protagonizado por dos laicos se conserva en la Colección Documental del Fraile y lleva el largo y explícito título de Diálogo entre un egoísta misántropo y un buen patriota sociable, que en el casual encuentro de la mesilla de un café hacia el rincón de una pieza poco concurrida trabaron combate verbal a medio tono (por evitar los estrechos bloqueos de las tropas ambulantes que regularmente hay en tales sitios) y al fin quedó el misántropo rendido a discreción del amigo de la patria y de su especie ${ }^{27}$. El ardiente patriota quiere batir a metralla al egoísta con las razones de la corrección fraternal pues no comprende sus ideas narcisistas en estos tiempos de guerra y de patriotismo. El leal defensor de la causa de España, a instancias del egoísta, le

${ }^{27}$ Diálogo entre un egoísta misántropo y un buen patriota sociable, s.l., s.n., s.a. En Cádiz se imprimió en 1808 con el título de El tacaño convertido. 
dice lo que ha hecho por la causa: entregar su capital, llevar a sus hijos al ejército, mantenidos por él mismo, y poner a su casa en una rígida economía. Además, añade: "¿Acaso la nobleza heredada sin la adquirida por la ciencia, el valor, o la virtud sirve para formar el completo de un hombre verdaderamente noble?» (p. 8). En una acotación señala el autor que, después de esta imprecación, el egoísta apoyó su frente sobre las dos manos y el bastón y así estuvo algún rato, hasta que finalmente le comunicó:

«Al fin ha triunfado usted de mí completamente, pues no pudiendo resistir mas tiempo la fuerza de sus poderosas y convincentes razones, no solo me entrego y rindo a su discreción, sino que le suplico su dictamen y opinión de lo que yo debo practicar para llenar todos los deberes que usted me ha hecho conocer» (p. 13).

Pedro Riaño de la Iglesia hace hincapié en la idea de que el patriota manifiesta en la discusión ideas contrarias a la existencia de los mayorazgos, lo cual indica la renovación jurídica que se había operado en la sociedad española al verificarse la revolución antinapoleónica ${ }^{28}$.

Se publicó en Cádiz otra conversación cuyo tema era la denigración de la Inquisición. Se tituló Conversación entre el Cura y el Boticario de la villa de Porriño sobre el tribunal de la Inquisición ${ }^{29}$. En El Redactor General se hacía un extracto de la misma y se decía que el autor de este diálogo se proponía responder a las objeciones que se pudieran hacer a favor de la Inquisición, y que lo desempeña con sólidas razones y testimonios de las Sagradas Escrituras y de los Santos Padres. Hace presente que sin este Tribunal subsiste y ha subsistido el catolicismo en muchos países, que no se propaga por medio de la fuerza; y que si en España se conserva la religión ha sido debido a las virtudes de la misma y no a la Inquisición. Expone además el gravamen que supone para el país el mantenimiento de dicho tribunal cuyos individuos habitan en palacios, pasean en buenos coches y tienen lacayos con sus rentas. Señalaba el autor de la reseña que el lector acabaría instruido en la pura moral de la Escritura ${ }^{30}$. No faltó, por supuesto, otro folleto que criticara a éste, y así se publicó en 1814 una Respuesta familiar a las erradas máximas del cura de Porriño, por el Doctor Don Juan Pablo Constans, Canónigo de la Colegiata de Pons ${ }^{31}$.

${ }^{28}$ Pedro RiAÑo DE LA IGLESIA, La imprenta en la isla gaditana durante la Guerra de la Independencia: libros, folletos y hojas volantes (1808-1814), ensayo bio-bibliográfico documentado, ed. de José Manuel Fernández Tirado y Alberto Gil Novales, Madrid, Ediciones del Orto, 2004, I, p. 255.

${ }^{29}$ Conversación entre el Cura y el Boticario de la villa de Porriño sobre el tribunal de la Inquisición, Cádiz, s.n., 1812; Manresa, Ignacio Abad, 1814.

${ }^{30}$ El Redactor General, n. ${ }^{\circ}$ 596, 30 de enero de 1813, p. 2382.

31 Muchísimos libelos en contra del Tribunal salieron de la pluma de los escritores liberales. Citamos como ejemplo sólo dos de ellos: el folleto en prosa de MARTínEZ DE LA ROSA, Incompatibilidad de la libertad española con el restablecimiento de la Inqui- 
Recordamos los diálogos, coloquios y conversaciones de Lucas Alemán, anagrama de Manuel Casal y Aguado ${ }^{32}$, que escribió con un tono muy festivo y con intereses patrióticos y políticos. El primero de ellos, El gallo vocinglero que no pone y aturde al gallinero. Madrid por dentro, coloquio entremesado o remiendo de otro asainetado entre Aldonza Terrones y el tío Chivo, que pasó lo mismito que lo escribo ${ }^{33}$, está fechado en 1813 . Se trata, con sus propias palabras, de una jocosa invectiva que satiriza varios abusos vulgares y el aparente patriotismo que tuvieron algunos españoles. Más fama tuvo el titulado El Mirlo, obsequio de Madrid a la llegada de las Cortes, diálogo entre Don Lucas Alemán y Don Martín Tudesco ${ }^{34}$, invención que refería las funciones públicas que hizo Madrid a la venida de las Cortes el 5 de enero de 1814. Lucas cuenta a Martín cómo fue la llegada del Congreso y Martín alaba dicha institución:

\author{
«Creo que su vigilante \\ e infatigable desvelo, \\ hará la España feliz \\ y podemos prometernos \\ grandes venturas» (p. 4).
}

sición, demostrada por Ingenio Tostado, Cádiz, Imprenta de Vicente de Lema, 1811; y la divertida «égloga sepulcral» titulada La muerte de la Inquisición, que tiene como protagonistas a Panesio (trasunto del marqués de Villapanés), Rancinoso (o sea el Filósofo Rancio) y Simpliciano (autor del Diccionario razonado). El autor imita felizmente la primera égloga de Garcilaso, introduciendo a estos pastores serviles que se lamentan de la muerte del Santo Oficio tenebroso. Comienza así: «El triste lamentar de dos serviles / Panesio juntamente y Rancinoso.» (La muerte de la Inquisición, s.l., Imprenta Nacional, s.a., p. 1).

32 Nació en Madrid (1751-1837). Obtuvo diversas distinciones y puestos en el cargo de la medicina. Tradujo obras referentes a esta disciplina y colaboró en diferentes medios de comunicación. Su carácter festivo le llevó a cultivar la poesía satírica y folletos humorísticos. Además de La Paxarera, Madrid, Imprenta de Repullés, 1813 y Quisicosa del día o lo que habrá en Madrid el 14 del corriente, Madrid, Imprenta de Álvarez, 1813, escribió con posterioridad a la Guerra de la Independencia, El gavilán volando, o sea, el tribunal de los descontentos y mártires casados, Letrilla política, El Mochuelo Literario, todos ellos en 1820; La Calandria Constitucional y El Papagayo Vocinglero, en 1821, El doctor Zorrilla en 1827 y la comedia Don Lucas y Don Martín solos en su camerín en 1832. Alemán se atribuye también la composición de unos sainetes patrióticos no localizados en la actualidad: Los franceses en Getafe, representación en casa particular y La toma de Panzacola por las armas españolas. Francisco Aguilar Piñal dedica un artículo al prolífico escritor: «Noticias del Índice de comedias de Manuel Casal y Aguado», Cuadernos bibliográficos, 28 (1972), pp. 153-162.

33 L. Alemán, El Gallo vocinglero, que no pone y aturde al gallinero. Madrid por dentro. Por el autor de Las Cotorras y anteriores. Coloquio entremesado o remiendo del otro asaineteado, Madrid, Imprenta de Repullés, 1813.

${ }^{34}$ L. Alemán, El Mirlo, obsequio de Madrid a la llegada de las Cortes, el día 5 de enero del presente año de 1814, diálogo entre Don Lucas Alemán y Don Martín Tudesco, Madrid, Imprenta de Repullés, 1814. Este diálogo lo cita Jenaro ALENDA Y MirA, Relaciones de solemnidades y fiestas públicas de España, Madrid, Sucesores de Rivadeneyra, 1903, I, n. ${ }^{\circ} 2452$ (p. 184). 
Cuenta Lucas cómo adornaron las calles, el arco de triunfo y sus inscripciones, el engalanamiento de la puerta de Atocha, el obelisco al dos de mayo, las colgaduras, la iluminación, los bailes:
«El del Príncipe muy serio,
vestido de majestad
con un grande manto regio
$\mathrm{y}$ un retrato parecido
a Fernando como a un huevo.
El de la Cruz con vestido
de danzante, y en los trechos
unos rótulos muy grandes,
por cierto que el uno de ellos
decía Pérez, y yo
creí que fuese el Librero,
hasta que leí Perez-ca
Napoleón» (p. 13).

Martín le confiesa a su amigo que sabe que tiraron octavas suyas en el suyo, pero que le parecieron que estaban escasas de sublimidad de metro. A esto le contesta Lucas de forma tajante, reflejando la realidad que se había dado durante toda la guerra:
«¿Por qué? ¿por qué no trataban
el asunto con los huecos
piropos y rimbombadas
de poetas circunspectos?
No amigo, lo que yo escriba
quiero que mi zapatero
lo entienda. Jamás gusté
hablar a tientas, y menos
en las cosas que conviene
las sepa el sabio y el necio.
Supongamos que yo escribo
estos tenebrosos versos:
Ya la Transpirenaica turva bélica afirma a los Coturnos los talares del Numen tutelar de la rapiña, y pretérita guía sus Phalanges más allá del nevado Promontorio que entre la Iberia y Galia pone margen.
Pues toda esta faramalla de voces no es mas en pelo que decir: ya los Franceses marcharon echando ternos» (p. 14).

En El Vencejo, sátira que critica los abusos del carnaval. Diálogo con los mismos personajes que el anterior ${ }^{35}$ expresa Manuel de Casal su siem-

${ }^{35}$ L. Alemán, El Vencejo, sátira que critica los abusos del carnaval. Diálogo con los mismos personajes que el anterior, Madrid, Imprenta de Repullés, 1814. 
pre radical opinión en cuanto a la candente cuestión de los bandos políticos rivales:

\author{
«Liberales y serviles \\ para mí son una gerga \\ que entiendo cada vez menos, \\ y ruego a Dios no la entienda. \\ Religión, amigo mío, \\ Patria, leyes y conciencia \\ deben ser ídolos nuestros» (p. 3).
}

Citamos, para finalizar, La Codorniz, Madrid gozoso. Conversación que tuvieron desde balcón a ventana, la noche del veinte y ocho Juanita y la tía Blasa ${ }^{36}$. Se trata de un papel gratulatorio al regreso de Fernando VII. Después de algunos versos comienza un diálogo entre Blasa, vieja de setenta y dos años y su vecina Juanita, de veinte, en el que se pinta el júbilo de los madrileños en la segunda noche de iluminación por la noticia de la llegada del rey a Gerona. Juana recuerda:

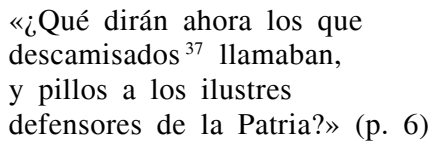

Ella misma concluye pensando que ahora habrá muchos afrancesados arrepentidos, y los disculpa: «Son al fin hermanos nuestros / y les cegó su ignorancia» (p. 7).

${ }^{36}$ L. AlemÁn, La Codorniz, Inventiva gratulatoria y justo regocijo a la venida de nuestro Augusto Soberano el Sr. Don Fernando VII. Madrid gozoso. Conversación que tuvieron desde balcón a ventana, la noche del veinte y ocho Juanita y la tía Blasa, Madrid, Imprenta de Repullés, 1814. También lo recoge J. ALENDA Y MIRA, Relación de solemnidades, . $^{\circ}$ 2454, pp. 184-185.

${ }^{37}$ El festivo médico escribía la definición de descamisados: «dictado honorífico que los bonapartinos daban a los españoles prisioneros, quando entraban en la corte desnudos y descalzos por la rapiña de sus opresores.» (L. ALEMÁN, La golondrina, que en vez de cantar rechina. Diccionario irónico, patético, transpirenaico, extractado de la Biblioteca del sufrimiento español en la dominación francesa, Madrid, Imprenta de Repullés, 1814, p. 12). 